\title{
Characterization of gastric-mucosal membranes
}

\author{
Distribution of lipid-and protein-associated amino groups across pig gastric microsomes
}

\author{
Parimal C. SEN and Tushar K. RAY* \\ Department of Surgery, The State University of New York, Upstate Medical Center, Syracuse, \\ NY 13210, U.S.A.
}

\section{(Received 15 December 1981/Accepted 10 February 1981)}

\begin{abstract}
Two $\mathrm{NH}_{2}$-reactive probes (2,4,6-trinitrobenzesulphonic acid and 1-fluoro-2,4-dinitrobenzene) were used to study the vectorial orientation of the membrane-associated free $\mathrm{NH}_{2}$ groups across pig gastric microsomal vesicles. Unlike 1-fluoro-2,4-dinitrobenzene, 2,4,6-trinitrobenzenesulphonic acid is ordinarily an impermeant probe that becomes permeant in the presence of $\mathrm{K}^{+}$and valinomycin. Although 2,4,6-trinitrobenzenesulphonic acid alone reacts with about $28 \%$ of the total microsomal phosphatidylethanolamine, 2,4,6-trinitrobenzenesulphonic acid in the presence of valinomycin plus $\mathrm{K}^{+}$or 1-fluoro-2,4-dinitrobenzene alone reacted with $75 \%$ of the phosphatidylethanolamine. Under similar conditions the free $\mathrm{NH}_{2}$ groups associated with the microsomal proteins also exhibited an asymmetric labelling pattern, the intra- and extravesicular orientation being 74 and $26 \%$ respectively.
\end{abstract}

The $\mathrm{NH}_{2}$-containing phospholipids, such as phosphatidylethanolamine and phosphatidylserine, have recently been reported to be distributed asymmetrically across different biological membranes like erythrocytes (Gordesky et al., 1975; Marinetti \& Love, 1976), mitochondrial inner and outer membranes (Marinetti et al., 1976; Nilsson \& Dallner, 1977; Krebs et al., 1979), microsomes (Nilsson \& Dallner, 1977; Higgins \& Dawson, 1977; Sundler et al., 1977), synaptosomes (Fontaine et al., 1980) and Golgi membranes (Nillson \& Dallner, 1977; Sundler et al., 1977). Asymmetric distribution of protein-bound $\mathrm{NH}_{2}$ groups across erythrocyte membranes has also been suggested (Marinetti \& Love, 1976). Such studies necessitate prior knowledge of the degree of purity and tightness and sidedness of the membrane vesicles to get meaningful data. The purified gastric microsomes are well-suited for such studies since these membranes have previously (Forte \& Lee, 1977; Sachs et al., 1977; Lee et al., 1979) been characterized as nearly homogeneous tightly-sealed vesicles. Thus these vesicles are highly enriched in $\mathrm{K}^{+}$-stimulated ATPase, which is stimulated severalfold in the presence of valinomycin (Forte \& Lee, 1977; Sachs et al., 1977; Lee et al., 1979). The $\mathrm{K}^{+}$ ionophore also induces a rapid accumulation of 9-aminoacridine (Lee et al., 1979) by the microsomes in the presence of $\mathrm{K}^{+}, \mathrm{Mg}^{2+}$ and ATP. The

\footnotetext{
* To whom reprint requests should be addressed.
}

studies suggested that most of the $\mathrm{K}^{+}$-stimulated ATP hydrolytic sites of these tight microsomal vesicles are exposed to the vesicle exterior.

The present paper deals with the vectorial distribution of the phosphatidylethanolamine and proteinbound $\mathrm{NH}_{2}$ groups across the purified microsomes from the pig fundic mucosa, using the impermeant probe 2,4,6-trinitrobenzenesulphonic acid, which becomes permeant in the presence of $\mathrm{K}^{+}$plus valinomycin (Gordesky et al., 1975) and the penetrating probe 1-fluoro-2,4-dinitrobenzene (Gordesky et al., 1975). Our data demonstrate that under optimal conditions about $75 \%$ of the total gastric microsomal phosphatidylethanolamine reacts with either 2,4,6-trinitrobenzenesulphonic acid or 1-fluoro-2,4dinitrobenzene, the intra- and extra-vesicular orientation being $58 \%$ and $17 \%$ respectively. Since $25 \%$ of the total phosphatidylethanolamine does not react with the probes except in detergent-treated microsomes it is not possible to predict their orientation. The microsomal protein-bound $\mathrm{NH}_{2}$ groups also exhibit an asymmetric distribution, the intra- and extra-vesicular orientation being $74 \%$ and $26 \%$ respectively. The quantitative values for the membrane-bound $\mathrm{NH}_{2}$ groups across the gastric microsomal vesicles reported in the present paper have been calculated after taking into account the proportion of leaky vesicles in the microsomal population and hence are somewhat different from those previously reported (Ray et al., 1980; Sen et al., 1980). 


\section{Methods and materials}

Fresh pig stomachs were purchased from the local slaughterhouse. The gastric microsomal membranes were harvested by a procedure described previously (Ray, 1978). The proteins were assayed by the procedure of Lowry et al. (1951).

The ATPase was assayed as previously described (Ray, 1978). Briefly, the incubation mixture contained, in a total volume of $1 \mathrm{ml}, 50 \mu \mathrm{mol}$ of Pipes (piperazine-1,4-diethanesulphonic acid) buffer (pH6.8), $1 \mu \mathrm{mol}$ of $\mathrm{MgCl}_{2}, 2 \mu \mathrm{mol}$ of Tris/ATP, $150 \mu \mathrm{mol}$ of $\mathrm{KCl}, 20 \mu \mathrm{g}$ of membrane protein in the presence and absence of $10 \mu \mathrm{M}$-valinomycin. After $6 \mathrm{~min}$ incubation at $37^{\circ} \mathrm{C}$ the reactions were stopped by $1 \mathrm{ml}$ of $12 \%$ trichloroacetic acid. The $P_{1}$ was assayed by the procedure of Sanui (1974). The valinomycin-stimulated ATPase activity was calculated as the rate of $P_{i}$ production in presence of valinomycin minus the rate in the absence of the ionophore.

Vesicular accumulation of $\mathrm{H}^{+}$was measured at room temperature by the method of Lee et al. (1979) using the change in fluorescence intensity (quenching) of 9-aminoacridine, which is proportional to the amount of dye taken up by the microsomes.

Labelling of the microsomal phosphatidylethanolamine with 2,4,6-trinitrobenzenesulphonic acid (Pierce Chemical Co.) or 1-fluoro-2,4-dinitrobenzene (Eastman Kodak) was done by incubating the microsomes $(1 \mathrm{mg})$ with different concentrations of freshly prepared 2,4,6-trinitrobenzenesulphonic acid $(1-5 \mathrm{mM})$ or 1-fluoro-2,4-dinitrobenzene (1-2 mM) in $250 \mathrm{~mm}$-sucrose/5 mM-Pipes/Tris buffer (pH6.0-9.0) for $15-90 \mathrm{~min}$ at room temperature. To make 2,4,6-trinitrobenzenesulphonic acid permeable to the microsomal vesicles $150 \mathrm{~mm}-\mathrm{K}^{+}$ and $10 \mu \mathrm{M}$-valinomycin was included in the assay medium. The reactions were stopped by dilution with about $10 \mathrm{vol}$. of ice-cold sucrose/Pipes/Tris buffer of appropriate $\mathrm{pH}$ and centrifuged for $60 \mathrm{~min}$ at $150000 \mathrm{~g}$. The lipids were extracted from the pellet by the method of Bligh \& Dyer (1959). The pellet after lipid extraction was used for quantification of 2,4,6-trinitrobenzenesulphonic acid bound to protein. The lipid extract was concentrated under $\mathrm{N}_{2}$ and the trinitrobenzyl phosphatidylethanolamine and dinitrobenzyl phosphatidylethanolamine were separated from free phosphatidylethanolamine by t.l.c. $(0.25 \mathrm{~mm}$ plate thickness; Merck Silica gel) with chloroform/methanol/water $(65: 25: 4$, by vol.) as solvent system. The derivatives could be located from the yellow colour and free phosphatidylethanolamine was detected with the ninhydrin spray reagent. The bands of phosphatidylethanolamine and its derivatives were scraped off, extracted twice with $3 \mathrm{ml}$ of chloroform/methanol $(1: 1, \mathrm{v} / \mathrm{v})$ and assayed for lipid phosphorus by the
Bartlett (1959) procedure. The trinitrobenzyl phosphatidylethanolamine and dinitrobenzyl phosphatidylethanolamine were also quantified by measuring the light absorption at 337 and $345 \mathrm{~nm}$ respectively.

The delipidated membranes described above were dissolved in $3 \mathrm{ml}$ of $1 \%$ sodium dodecyl sulphate and the absorbance was read at $337 \mathrm{~nm}$ for trinitrobenzyl-protein and $345 \mathrm{~nm}$ for dinitrobenzyl-protein (Marinetti \& Love, 1976). The absorbance values were converted into nmoles from a standard curve drawn by plotting the absorbance of different concentrations of trinitrobenzylvaline against the concentration of valine.

\section{Results and discussion}

The microsomes used in the present study were highly enriched in valinomycin-stimulated ATPase. The $\mathrm{K}^{+}$-stimulated ATPase activities measured as the rate of $\mathrm{P}_{1}$ production at $37^{\circ} \mathrm{C}$, before and after addition of $10 \mu \mathrm{M}$-valinomycin, were $4.8-6.5$ and $25-30.5 \mu \mathrm{mol} / \mathrm{h}$ per $\mathrm{mg}$ of protein respectively. Fluorescence quenching of 9-aminoacridine induced by valinomycin under the conditions described above using $200 \mu \mathrm{g}$ of microsomes was $70-80 \%$. These data suggest that the microsomes used in the present study were predominantly (about $85 \%$ ) in the form of tightly sealed vesicles and had most of the ATP hydrolytic sites facing the extravesicular space.

Pig gastric microsomes contain the highest amount of phosphatidylethanolamine $(96.1 \mathrm{nmol} /$ $\mathrm{mg}$ ) representing $40.4 \%$ of the total phospholipids and a trace amount $(0.7 \%)$ of phosphatidylserine (Sen \& Ray, 1979a).

Fig. 1 shows the effects of different concentrations of 2,4,6-trinitrobenzenesulphonic acid on the labelling of gastric microsomal phosphatidylethanol-

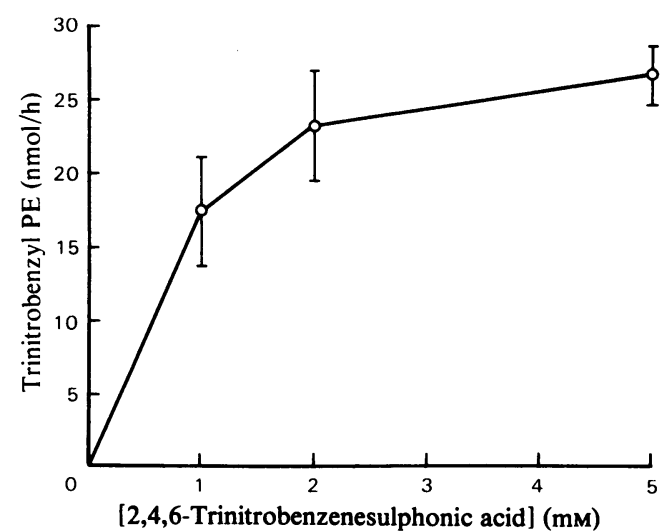

Fig. 1. Effects of different concentrations of 2,4,6-trinitrobenzenesulphonic acid on the labelling of phosphatidylethanolamine $(P E)$ associated with pig gastric microsomes

Data are from three separate experiments \pm S.E.M. 
amine in the absence of valinomycin plus $\mathrm{K}^{+}$. Optimum labelling was observed with $2 \mathrm{~mm}$ 2,4,6-trinitrobenzenesulphonic acid.

The kinetics of labelling of microsomal phosphatidylethanolamine by 2,4,6-trinitrobenzenesulphonic acid is shown in Fig. 2. The labelling was complete within $15 \mathrm{~min}$ in $2 \mathrm{~mm}$-2,4,6-trinitrobenzenesulphonic acid compared with $30 \mathrm{~min}$ with a lower plateau in $1 \mathrm{mM}-2,4,6$-trinitrobenzenesulphonic acid, suggesting that the optimum concentration of 2,4,6-trinitrobenzenesulphonic acid for the labelling of microsomal phosphatidylethanolamine would be around $2 \mathrm{~mm}$. The slight increase in labelling with $5 \mathrm{~mm}$ 2,4,6-trinitrobenzenesulphonic acid (Fig. 1) may be due to partial penetration of the probe at high concentrations.

The data in Table 1 demonstrate the effect of pH on the labelling of microsomal phosphatidylethanolamine by 1-fluoro-2,4-dinitrobenzene and 2,4,6-trinitrobenzenesulphonic acid (with and with-

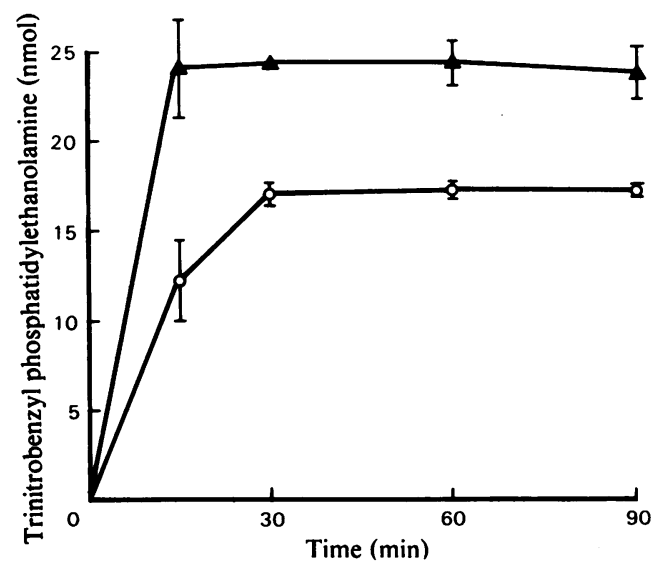

Fig. 2. Kinetics of reaction of 2,4,6-trinitrobenzenesulphonic acid with gastric microsomal phosphatidylethanolamine

Data are from three separate experiments, $O$, $1 \mathrm{mM}-2,4,6$-trinitrobenzenesulphonic acid; $\Delta$,

2 mM-2,4,6-trinitrobenzenesulphonic acid. out valinomycin plus $\mathrm{K}^{+}$). Maximum labelling of phosphatidylethanolamine was observed at pH8.0. 2,4,6-Trinitrobenzenesulphonic acid, which is ordinarily a non-penetrating probe, can be made penetrating in the presence of valinomycin plus $\mathrm{K}^{+}$, thus exhibiting an extent of phosphatidylethanolamine labelling similar to the penetrating probe 1-fluoro-2,4-dinitrobenzene (Table 1). The data show that at $\mathrm{pH} 8.0$ inclusion of valinomycin plus $\mathrm{K}^{+}$elevates the labelling by 2,4,6-trinitrobenzenesulphonic acid from $28 \%$ of the total microsomal phosphatidylethanolamine to $75 \%$. Considering about $15 \%$ of the vesicles were leaky, hence non-responsive to valinomycin plus $\mathrm{K}^{+}$, the corrected values for extra- and intra-vesicular phosphatidylethanolamine would be 16 and $56 \mathrm{nmol} / \mathrm{mg}$ of protein respectively.

2,4,6-Trinitrobenzenesulphonic acid also reacts with the free $\mathrm{NH}_{2}$ groups of the membrane protein, approaching a plateau around $2 \mathrm{mM}$ (Fig. $3 a$ ). There was more trinitrobenzyl-protein in the presence than in the absence of valinomycin plus $\mathrm{K}^{+}$(Fig. $3 b$ ). From the extent of interaction of 2,4,6-trinitrobenzenesulphonic acid with the protein $\mathrm{NH}_{2}$ groups in the presence and the absence of valinomycin plus $\mathrm{K}^{+}$(Fig. $3 b$ ), and taking into account that $15 \%$ of the vesicles were leaky, it is calculated that the protein-bound free $\mathrm{NH}_{2}$ groups exposed to the vesicle exterior are $11.8 \mathrm{nmol} / \mathrm{mg}$ of protein, the remaining $45 \mathrm{nmol}$ being within the vesicles. The $\mathrm{NH}_{2}$ groups exposed to the vesicle exterior have recently been demonstrated to play critical roles in ATPase function (Ray et al., 1980).

It should be noted that about $25 \%$ of the phosphatidylethanolamine did not react with any of the probes (Table 1), although both probes reacted with over $95 \%$ of the phosphatidylethanolamine when the microsomes were solubilized with Triton X-100 (Table 2). Similar failure of a significant portion (about $40 \%$ ) of the total phosphatidylethanolamine being labelled by permeant probes has been reported for erythrocyte ghosts (Bonsall

Table 1. Effects of different pH values on the labelling of gastric microsomal phosphatidylethanolamine by 2,4,6trinitrobenzenesulphonic acid or 1-fluoro-2,4-dinitrobenzene

Labelling with 2,4,6-trinitrobenzenesulphonic acid or 1-fluoro-2,4-dinitrobenzene was done at a concentration of $2 \mathrm{mM}$. $\mathrm{K}^{+}(150 \mathrm{~mm})$ plus $10 \mu \mathrm{M}$-valinomycin $\left(\mathrm{Val}-\mathrm{K}^{+}\right)$was used when indicated. Details are given in the Methods and materials section. Data are means \pm S.E.M. $(n=4)$.

$\begin{array}{cccc}\text { Trinitrobenzyl phosphatidylethanolamine } & \begin{array}{c}\text { Proportion of total } \\ \text { phosphatidylethanolamine }\end{array} & \text { Dinitrobenzyl phosphatidylethanolamine } & \begin{array}{c}\text { Proportion of total } \\ \text { phosphatidylethanolamine }\end{array} \\ \text { (nmol/mg of protein) } & (\%) \\ \text { (17.7 } \pm 1.9 & 18.4 & 56.5 \pm 3.0 & 58.8 \\ 50.0 \pm 3.2 & 52.0 & 58.3 \pm 4.5 & 60.7 \\ 27.0 \pm 2.8 & 28.1 & 76.0 \pm 3.0 & 73.2 \\ 72.0 \pm 5.0 & 75.0 & 75.5 \pm 3.5 & 78.6 \\ 72.5 \pm 6.0 & 75.5 & 75.8 \pm 4.5 & 78.9\end{array}$

Vol. 195 
Table 2. Labelling of microsomal phosphatidylethanolamine with 2,4,6-trinitrobenzenesulphonic acid in the presence or absence of Triton $X-100$

The labelling was carried out at pH8.0. Details are given in the Methods and materials section. Data are means \pm S.E.M. $(n=3)$.

\section{Conditions}

2,4,6-trinitrobenzenesulphonic acid (with Val- $\mathrm{K}^{+}$)

2,4,6-trinitrobenzenesulphonic acid (with $0.1 \%$ Triton)

2,4,6-trinitrobenzenesulphonic acid (with $1.0 \%$ Triton)
Trinitrobenzyl phosphatidylethanolamine ( $\mathrm{nmol} / \mathrm{mg}$ of protein)

$$
\begin{array}{r}
70.0 \pm 3.5 \\
78 \pm 3.2 \\
92.1 \pm 2.0
\end{array}
$$

Proportion of total phosphatidylethanolamine labelled (\%)

72

81.0

96.0

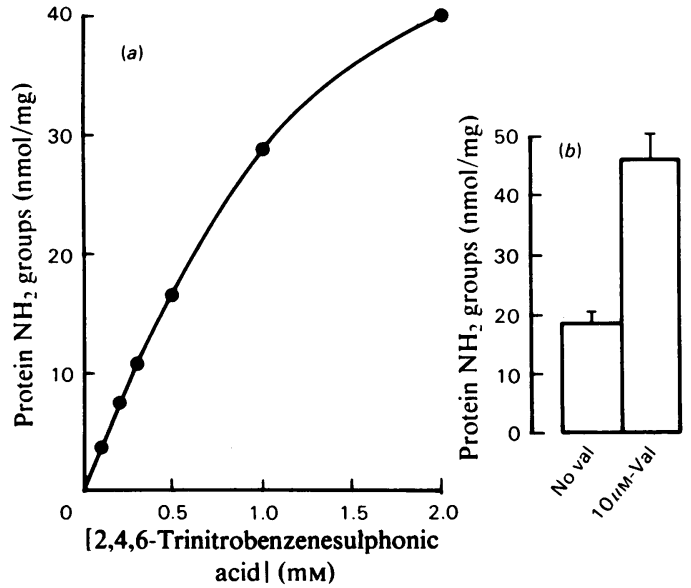

Fig. 3. Labelling of the protein-bound $\mathrm{NH}_{2}$ groups by 2,4,6-trinitrobenzenesulphonic acid

(a) shows the effects of different concentrations of 2,4,6-trinitrobenzenesulphonic acid in the presence of $150 \mathrm{mM}-\mathrm{K}^{+}$and $10 \mu \mathrm{M}$-valinomycin; (b) shows the effects of $2 \mathrm{~mm}-2,4,6$-trinitrobenzenesulphonic acid in the presence and absence of valinomycin plus $\mathrm{K}^{+}$. Abbreviation used: Val, valinomycin plus $\mathrm{K}^{+}$. Results are means \pm S.E.M. $(n=3)$.

\& Hunt, 1971; Gordesky \& Marinetti, 1973) and mitochondrial particles (Marinetti et al., 1976; Krebs et al., 1979). This non-availability of a significant portion of the phosphatidylethanolamine of biological membranes to various $\mathrm{NH}_{2}$ reactive chemical probes appear to be due to some intrinsic molecular architecture of the biomembranes. Studies with the erythrocyte membranes (Marinetti \& Love, 1974) demonstrated that a significant portion (about $37 \%$ ) of the phospholipids was found to be in close proximity to the neighbouring proteins so that they could react with the $\mathrm{NH}_{2}$-cross-linking agent difluorodinitrobenzene. Such approaches using difluorodinitrobenzene may be useful for further characterization of the small amounts of microsomal phospholipids (about 4\%) demonstrated to be essential for the functional stability of the gastric $\mathrm{K}^{+}$-stimulated ATPase (Sen \& Ray, 1979b, 1980).

We thank Miss Susan Golden for typing the manuscript. This work was supported by a grant from the U.S. Public Health Service (AM 25544). T. K. R. is a recipient of Research Career Development Award AM 00623.

\section{References}

Bartlett, G. R. (1959) J. Biol. Chem. 234, 466-468

Bligh, E. G. \& Dyer, W. J. (1959) Can. J. Biochem. Physiol. 37, 911-917

Bonsall, R. W. \& Hunt, S. (1971) Biochim. Biophys. Acta 249, 281-290

Fontaine, R. N., Harris, R. A. \& Schroeder J. Neurochem. 34, 269-275

Forte, J. G. \& Lee, H. C. (1977) Gastroenterology 73, 921-926

Gordesky, S. E. \& Marinetti, G. V. (1973) Biochem. Biophys. Res. Commun. 50, 1027-1034

Gordesky, S. E., Marinetti, G. V. \& Love, R. (1975) J. Membr. Biol. 20, 111-132

Higgins, J. A. \& Dawson, R. M. C. (1977) Biochim. Biophys. Acta 470, 342-356

Krebs, J. J. R., Hauser, H. \& Carafoli, E. (1979) J. Biol. Chem. 254, 5308-5316

Lee, H. C., Breitbart, H., Berman, M. \& Forte, J. G. (1979) Biochim. Biophys. Acta 553, 107-131

Lowry, O. H., Rosebrough, N. J., Farr, A. L. \& Randall, R. J. (1951) J. Biol. Chem. 193, 265-275

Marinetti, G. V. \& Love, R. (1974) Biochem. Biophys. Res. Commun. 61, 30-38

Marinetti, G. V. \& Love, R. (1976) Chem. Phys. Lipids $16,239-254$

Marinetti, G. V., Senior, A. E., Love, R. \& Broadhurst, C. I. (1976) Chem. Phys. Lipids 17, 353-362

Nilsson, O. S. \& Dallner, G. (1977) Biochim. Biophys. Acta 464, 453-458

Ray, T. K. (1978) FEBS Lett. 92, 49-52

Ray, T. K., Meng-Ai, Z. \& Sen, P. C. (1980) in Hydrogen Ion Transport in Epithelia (Schulz, I., ed.), pp. 203215, Elsevier/North-Holland Biomedical Press, Amsterdam

Sachs, G., Spenney, J. G. \& Rehm, W. S. (1977) Int. Rev. Physiol. 12, 127

Sanui, H. (1974) Anal. Biochem. 60, 489-504

Sen, P. C. \& Ray, T. K. (1979a) Arch. Biochem. Biophys. 198, 548-555

Sen, P. C. \& Ray, T. K. (1979b) Biochem. J. 182, 637-640

Sen, P. C. \& Ray, T. K. (1980) Arch. Biochem. Biophys. 202, 8-17

Sen, P. C., Meng-Ai, Z. \& Ray, T. K. (1980) Arch. Biochem. Biophys. 205, 340-351

Sundler, R., Sarcione, S. L., Alberts, A. W. \& Vagelos, P. R. (1977) Proc. Natl. Acad. Sci. U.S.A. 74, 33503354 